SAE paper 2007-01-0583. Copyright (C) 2007 SAE International. This paper is posted on this site with permission from SAE International, and is for viewing only. Further use or distribution of this paper is not permitted without permission from SAE" 


\title{
Hydraulically Interconnected Suspension Parameter Sensitivity in Half-Car Ride Performance
}

\author{
W. Smith, N. Zhang and J. Jeyakumaran \\ Mechatronics and Intelligent Systems, University of Technology, Sydney, Australia
}

Copyright @ 2007 SAE International

\begin{abstract}
In this paper, the development of a hydraulically interconnected suspension (HIS) system model and the integration of this model into a four degree-of-freedom half-car system is briefly introduced. The appropriate frequency response functions are derived in order to simulate the system response to a stochastic road profile. The sprung mass vertical and roll accelerations, the dynamic normal tyre force, and the suspension deflection are considered in the frequency domain up to $20 \mathrm{~Hz}$. Four key hydraulic system parameters are identified and investigated to gauge their effects on the system's dynamic performance. The results indicate that HIS system performance can be greatly affected by these hydraulic parameters.
\end{abstract}

\section{INTRODUCTION}

Conventional vehicle suspension design involves a trade-off between handling stability and ride comfort. A vehicle with a relatively stiff suspension is likely to possess good handling stability but poor ride comfort, and vice versa. One approach to overcoming this compromise is through the use of hydraulic or mechanical interconnections between the individual wheel stations (spring-damper elements). An interconnected suspension system is one in which a displacement at one wheel station can produce forces at other wheel stations [1].

Interconnected suspensions, in theory, allow the designer to achieve greater control over the stiffness and damping of each suspension mode. The designer of a conventional non-interconnected suspension, however, remains reliant upon single-wheel stiffness and damping to implicitly define modal characteristics. The degree to which individual modes can be controlled depends on the exact method and arrangement of interconnection employed.

In recent experimental studies, vehicles with hydraulically interconnected suspension (HIS) systems displayed significantly improved handling capability in comparison to their non-interconnected 'equivalents' $[2,3]$. Meanwhile, a recent theoretical study concluded that, for a half-car model (consisting of a single set of 'typical' passenger vehicle parameters) subjected to a stochastic road input, the added roll stiffness achieved with an HIS system resulted in better ride comfort and smaller tyre normal force fluctuations than if the increased roll stiffness had been achieved with a stiffer conventional suspension [4]. A question arises, then, as to how the ride performance of an HIS-equipped vehicle might be affected by variations in the parameters of the hydraulic system.

In this paper, such an investigation of these effects is conducted. The study focuses on the sprung mass response to road roughness in the important frequency range from 0 to $20 \mathrm{~Hz}$ and, in particular, the way in which this response is affected by four hydraulic system parameters varied in isolation. The dynamic normal tyre force and suspension strut deflection are also considered to illustrate the broader effects of road roughness on each system's response.

\section{MODEL DESCRIPTION}

\section{SYSTEM DESCRIPTION}

Vehicle ride performance is often investigated theoretically using a quarter-car model, but this would obviously be too simple to illustrate interconnected suspension principles, where multiple wheel stations are inherently required. In an effort to retain simplicity, whilst still accounting for fluid interconnections between wheel stations, a lumped-mass four-degree-of-freedom half-car model is used in this investigation. Numerical simulations of a similar full-car model show that the halfcar simplification is capable of capturing the essential dynamics of the system [5]. The half-car, shown in Figure 1, is described by typical passenger vehicle parameters and consists of linear tyre damping and springing, linear conventional suspension springing, and a typical roll-plane right-left symmetric HIS system, similar in arrangement to that studied by Liu [6]. The system inputs are the road displacements at both tyre contact 'points' and the system outputs are the vertical displacements of the unsprung masses and the vertical and roll displacements of the sprung mass.

The hydraulic system consists of: a double-acting cylinder at each wheel-station; hydraulic interconnection between the cylinders; and gas-filled accumulators and damper valves, which provide the desired levels of springing and damping. The hydraulic circuits are 
arranged such that motion in a certain vehicle mode produces a nominal flow distribution which operates particular accumulators and dampers. The arrangement considered here may be described as anti-oppositional [7], meaning that stiffness is added to the vehicle roll mode without significantly affecting the bounce mode.

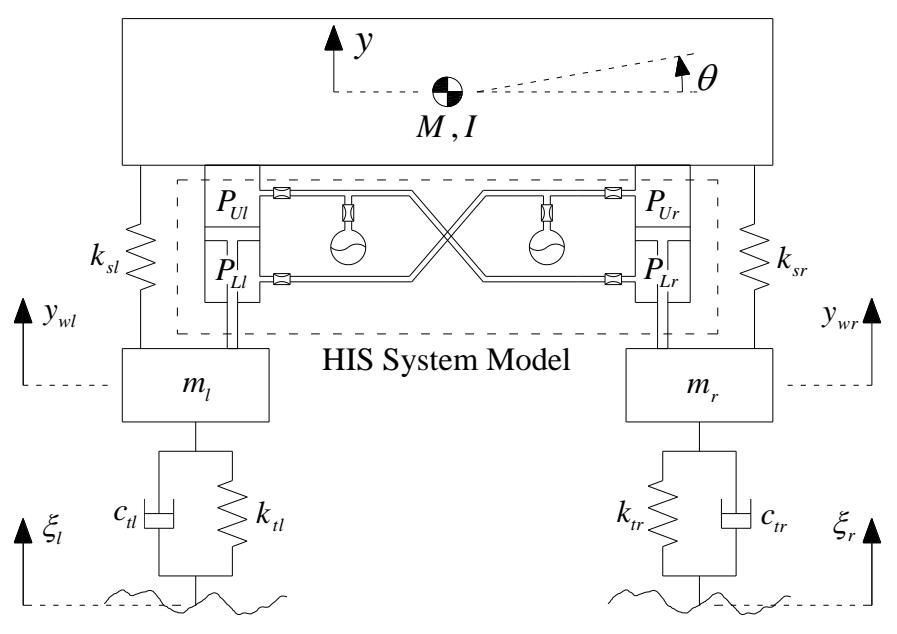

Figure 1: Layout of half-car with: an HIS

HIS systems might appear prima facie to have similar characteristics to anti-roll bars, yet there are a number of noteworthy conceptual differences between the two. First, HIS systems (depending on the specific arrangement) have the capability not only to add roll stiffness, but also to add roll damping. Thus the roll damping ratio may be held constant with the addition of roll stiffness, a feature of which conventional anti-roll bars are not readily capable. Second, HIS systems can add roll stiffness without significantly affecting the roll moment distribution, which is crucial for directional response and handling performance. Third, HIS systems have the broader capability, at least ideally, to independently control four-wheel vehicle modes [1]. For example, increased roll stiffness and decreased articulation stiffness may be achieved simultaneously, which is unachievable with an anti-roll bar.

The aim of this study is to compare the dynamic performance-particularly ride comfort-of the half-car system with a number of different hydraulic system parameter combinations. A 'base' combination of parameters is set, then a few 'key' parameters are adjusted in isolation to indicate their influence on ride comfort.

\section{PERFORMANCE INDICES AND METHODS OF EVALUATION}

Dynamic performance indices are a common tool employed to evaluate and/or optimise suspension system performance. The indices are usually set in the context of simplified quarter-car models and are based on mean square or root mean square (RMS) vehicle response to specified inputs. The most widespread of the considered response variables are the sprung mass vertical acceleration, the dynamic normal tyre force, and the relative displacement in the suspension strut [8], all of which are desirable to minimise. These responses are used to gauge, respectively, vehicle ride comfort, road holding, and suspension working space.

Here, since a half-car model is studied, vehicle ride comfort is assessed not only by sprung mass vertical acceleration, but also by sprung mass roll acceleration. Both acceleration responses are considered in terms of their Power Spectral Densities (PSDs) and are weighted according to human sensitivity, as described by ISO 2631-1 [9]. The aforementioned road holding and working space indicators are also assessed in their PSD forms.

Based on vehicle response to a specified road disturbance, the four performance indices for each parameter combination are compared qualitatively via response plots, rather than quantitatively via mean square or RMS values, although quantitative RMSbased performance evaluation would be a straightforward task.

The system is modelled by linearisation about the mean operating conditions, and advantage is taken of the model's linearity by considering system performance in the frequency domain, which is a convenient but nonessential approach. The key hydraulic system parameters selected for investigation are: the mean static system pressure; the linear cylinder valve loss coefficient; the linear accumulator valve loss coefficient; and the hydraulic fluid viscosity. Simulations suggest that these parameters, above all others, are crucial to HIS system performance.

No attempt is made here to investigate the handling performance of each parameter combination. Some recent experimental studies have demonstrated the potential handling superiority of HIS systems [2,3], so this paper begins with the presupposition that interconnected schemes have the capability to deliver handling improvements. A theoretical examination of this hypothesis, and of the influence of system parameters on handling performance, would require a more detailed vehicle model with the inclusion of parameters relevant to the vehicle's lateral dynamics. The road holding indicator employed herein must therefore be interpreted with caution since it is based on the tyre force due only to vertical dynamics, and consequently excludes important low frequency handling phenomena, such as the lateral load transfer resulting from vehicle roll. However, higher frequency, purely vertical dynamic tyre force fluctuation has been found to have an adverse effect on vehicle handling potential [10], so its application here is not without purpose.

\section{ROAD SURFACE DESCRIPTION AND VEHICLE RESPONSE}

Road profiles in vehicle dynamics modelling are generally treated as either deterministic (bumps, 
potholes etc.) or stochastic (random road roughness) processes [11]. Here, the latter approach is adopted. A completely random road profile, however, clearly poses a modelling challenge, and, perhaps more importantly, is in obvious disagreement with practical observation.

To overcome these difficulties, constraints must be placed on the nature of the road's randomness. It has been suggested, and is now commonly agreed upon, that such appropriate constraints are achieved by assuming the entire road surface to be a realisation of a two-dimensional Gaussian homogenous and isotropic random process $[12,13]$.

A single road profile can therefore be conveniently represented by its PSD function, with the assumption of homogeneity (i.e., possessing statistical properties independent of coordinate translations [14]) making the direct spectral densities of the right and left tracks equal. The assumption of isotropy (i.e., possessing statistical properties independent of coordinate rotations [14]) renders the cross-spectra between the tracks equal and implies, somewhat conveniently, that they are dependent only on the vehicle track width and the single-track direct spectral density.

The nature of isotropy carries with it a number of implications limiting the specification of the direct spectral density and the reader is directed to the relevant literature [13-16] lest the assumption be applied haphazardly. For our present purposes, a permissible and sufficient form of the direct spectral density is the ubiquitous 'single slope' representation, often expressed in terms of $\kappa$ the spatial frequency:

$$
S_{D}^{\xi}(\kappa)=c|\kappa|^{-2 w}
$$

The application of isotropy allows us to determine the road displacement spectral density matrix $\mathbf{S}^{\xi}$, which facilitates the calculation of the response spectral density matrix [17]:

$$
\mathbf{S}^{R}(\omega)=\mathbf{H}^{*}(s) \mathbf{S}^{\xi}(\omega) \mathbf{H}^{T}(s)
$$

where $\mathbf{H}$ is a matrix of the appropriate frequency response functions (FRFs) and the symbols ${ }^{*}$ and ${ }^{T}$ denote the complex conjugate and matrix transpose, respectively. The derivation of the FRFs matrix is explained in the next section.

\section{SYSTEM EQUATIONS AND FREQUENCY RESPONSE FUNCTIONS}

The equations of motion for the coupled half-car and hydraulic systems shown in the HIS vehicle in Figure 1 have been derived elsewhere [18] and are in the form:

$$
\begin{aligned}
& \mathbf{M} \ddot{\mathbf{Y}}+\mathbf{C} \dot{\mathbf{Y}}+\mathbf{K Y}=\mathbf{D P}+\mathbf{F}_{e x} \\
& \dot{\mathbf{P}}=\mathbf{N} \dot{\mathbf{Y}}+\mathbf{G}(s) \mathbf{P}
\end{aligned}
$$

$$
\mathbf{Y}=\left[y_{w l}, y_{w r}, y, \theta\right]^{T} \text { and } \mathbf{P}=\left[P_{L r}, P_{U l}, P_{L l}, P_{U r}\right]^{T} \text {. }
$$

Present space limitations preclude a discussion of the various terms, but it will be sufficient here to note that $\mathbf{N}$ and $\mathbf{D}$ are hydraulic system-dependent constants, while $\mathbf{G}$ is dependent on both the hydraulic system and the complex frequency $s$ and is derived using the linearised hydraulic impedance approach and the transfer matrix method.

After some manipulation, the FRFs matrix for the HIS vehicle is obtained:

$$
\begin{aligned}
\frac{\mathbf{Y}(s)}{\bar{\xi}(s)} & =\mathbf{T}(s) \\
& =\left\{s^{2} \mathbf{M}+s \mathbf{C}+\mathbf{K}-s \mathbf{D}[s-\mathbf{G}(s)]^{-1} \mathbf{N}\right\}^{-1} \overline{\mathbf{F}}(s)
\end{aligned}
$$

in which the displacement vector $\bar{\xi}=[\xi, 0,0]^{T}$ $=\left[\xi_{l}, \xi_{r}, 0,0\right]^{T}$ and $\overline{\mathbf{F}}$ is a $4 \times 4$ matrix comprising all zero elements except the upper two diagonal terms $\bar{F}_{11}(s)=\bar{F}_{22}(s)=s c_{t}+k_{t}$.

Upon setting $s=j \omega$, the FRFs describe the system displacement response to any harmonic road excitation. The FRFs for this system have been published elsewhere and are not repeated here [4].

The FRFs matrices describe the ratio of output to input for harmonic system displacements. However, we are concerned here primarily with evaluating ride comfort, road holding and working space, which cannot be assessed directly through displacement FRFs alone. We are therefore required, before proceeding any further, to develop FRFs corresponding to the system outputs required for the performance indices outlined previously. The matrix form of these FRFs represents the $\mathbf{H}$ matrix in equation (2).

Given the displacement FRFs matrix, one may easily derive the acceleration, tyre force and deflection FRFs matrices, defined as:

$$
\mathbf{T}^{a}(s)=\frac{s^{2} \mathbf{Y}(s)}{\xi(s)} \quad \mathbf{T}^{t}(s)=\frac{\mathbf{F}_{t}(s)}{\xi(s)} \quad \mathbf{T}^{d}(s)=\frac{\mathbf{Y}_{d}(s)}{\xi(s)}
$$

in which $\mathbf{F}_{t}=\left[F_{t l}, F_{t r}\right]^{T}$ is the tyre dynamic normal force vector and $\mathbf{Y}_{d}=\left[y_{d l}, y_{d r}\right]^{T}$ is the suspension strut deflection vector. We can now assemble the required FRFs matrix $\mathbf{H}$, such that:

$$
\mathbf{Y}^{R}(s)=\mathbf{H}(s) \xi(s)
$$

where 
$\mathbf{H}=\left[\begin{array}{cccc}T_{31}^{a} & T_{41}^{a} & T_{11}^{t} & T_{11}^{d} \\ T_{32}^{a} & T_{42}^{a} & T_{12}^{t} & T_{12}^{d}\end{array}\right]^{T}$

and the response vector, which contains the four variables used in the performance indices, is $\mathbf{Y}^{R}=\left[\ddot{y}, \ddot{\theta}, F_{t l}, y_{d l}\right]^{T}$, in which $F_{t l}=F_{t r}$ and $y_{d l}=y_{d r}$ due to the right-left vehicle symmetry. Equation (7) may be substituted into equation (2) to obtain the response spectral density matrix. The diagonal elements of this response matrix represent the direct spectral densities of the variables in $\mathbf{Y}^{R}$. It is these variables upon which the results in the following section are based, although the acceleration terms are frequency-weighted before evaluation [9].

\section{RESULTS AND DISCUSSION}

In this section, the vehicle PSD response is considered in the frequency domain up to $20 \mathrm{~Hz}$. An 'average' road type is simulated $\left(w=1.25, c=50 \times 10^{-8} \mathrm{~m}^{0.5}\right.$ cycle $^{1.5}$ [17]) at a vehicle speed of $10 \mathrm{~m} / \mathrm{s}$, although the speed has little effect here, since the 'wheelbase filtering' phenomenon does not feature in the roll-plane model [4].

Figure 2 shows the vehicle acceleration response PSDs with mean system pressure variation. Clearly, the mean system pressure has little influence on the bounce mode
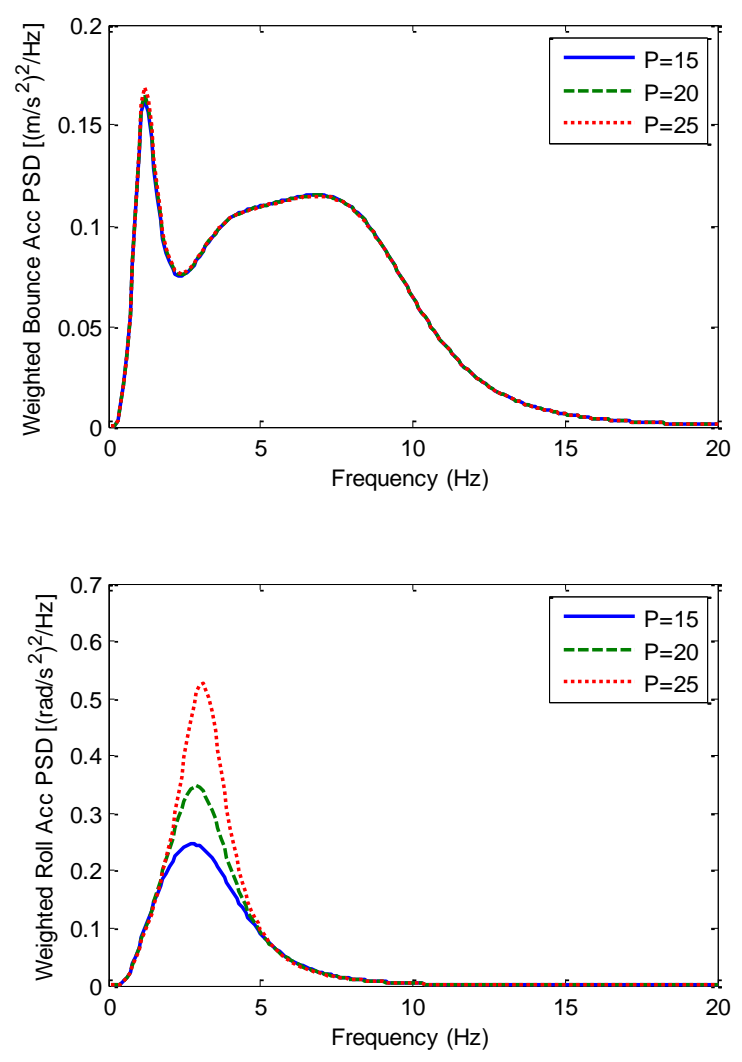

Figure 2: Acceleration PSDs with mean system pressure variation (in bar) response. Higher mean system pressure leads to a stiffer roll mode, and therefore poorer ride performance. This is to be expected, since the mean system pressure affects mainly the accumulators' performance, controlling the 'air-spring' effect. Due to the nature of the flow paths in each of the modes, the accumulators play only a very minor role during the bounce mode, but a significant role during the roll mode.

Figure 3 shows the tyre force and suspension deflection response PSDs with mean system pressure variation. The suspension deflection appears to be dominated by the bounce mode, hence the system pressure has little effect on working space performance. The system pressure does, however, affect the tyre force, and a higher pressure leads to reduced road holding performance.

The effect of the cylinder valve loss coefficient on ride comfort, and on road holding and working space, is shown in Figures 4 and 5, respectively. The cylinder valves control the bounce damping more than they do the roll damping, as reflected in Figure 4 . Also of note is that the valves appear to have the largest effect in the 4$8 \mathrm{~Hz}$ range, an effect which would be magnified by the ISO weighting curve, which is a maximum in that range. Figure 5 indicates that the cylinder valves have a complicated influence on road holding, such that characterisation as 'good' or 'bad' becomes frequency dependent. However, an increase in the cylinder valve loss coefficient seems to have an unambiguously positive effect on working space.
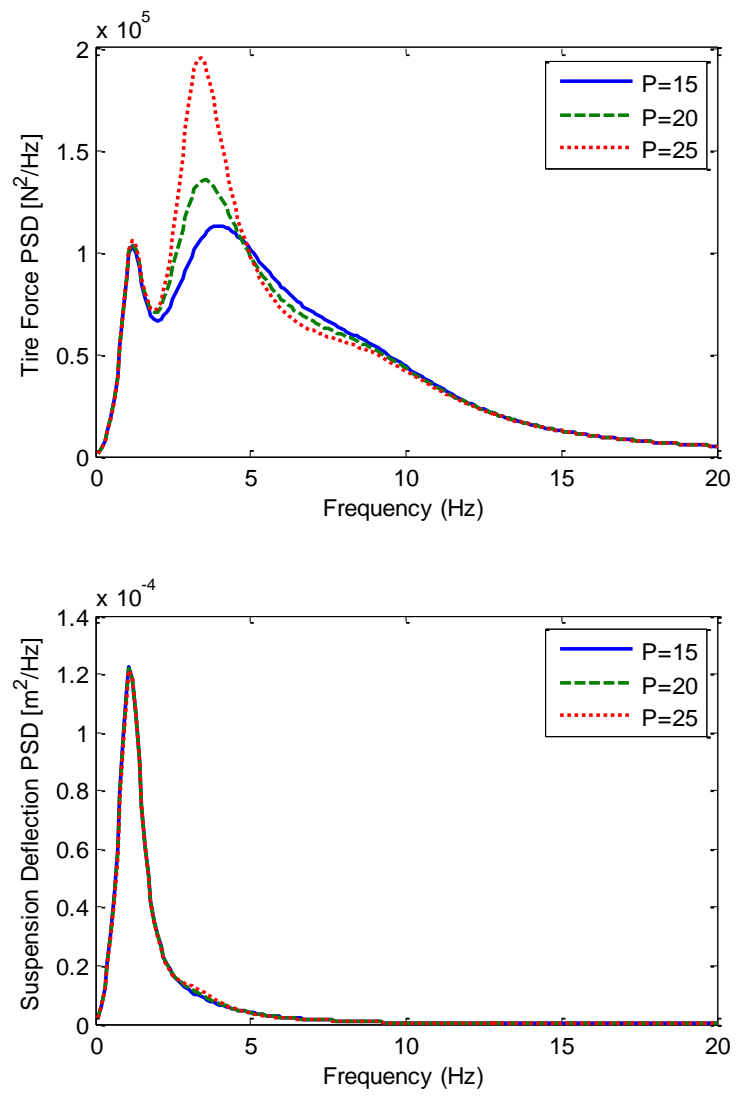

Figure 3: Tyre force and suspension deflection PSDs with mean system pressure variation (in bar) 

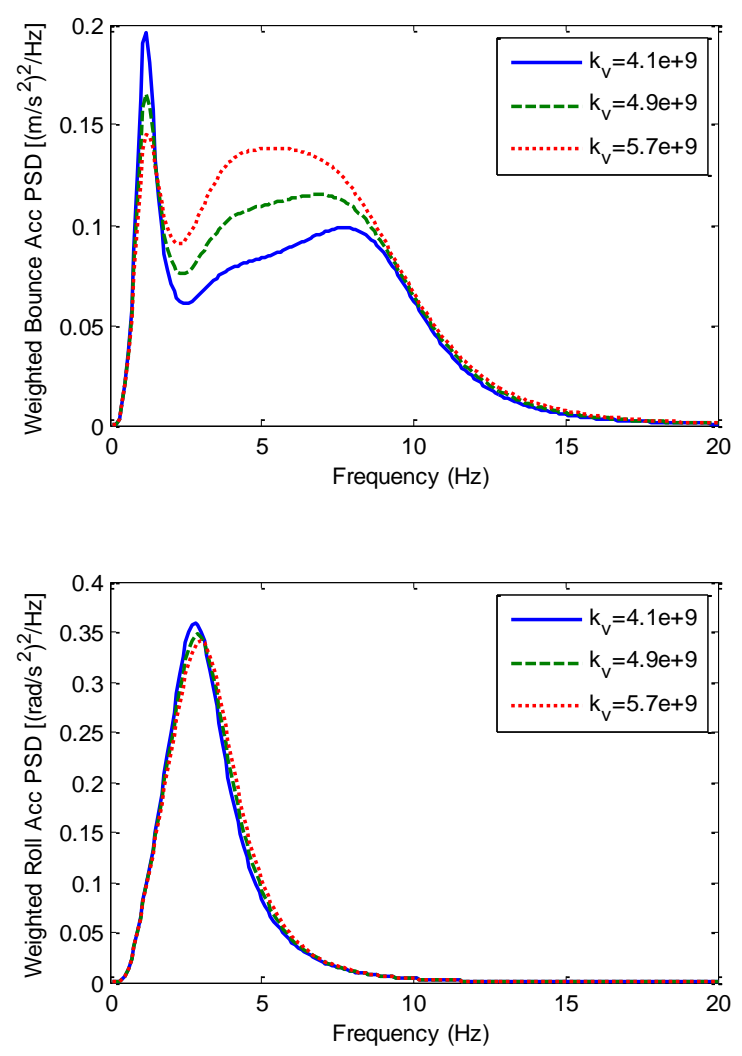

Figure 4: Acceleration PSDs with cylinder valve loss coefficient variation (in $\mathrm{kg} / \mathrm{s} . \mathrm{m}^{4}$ )
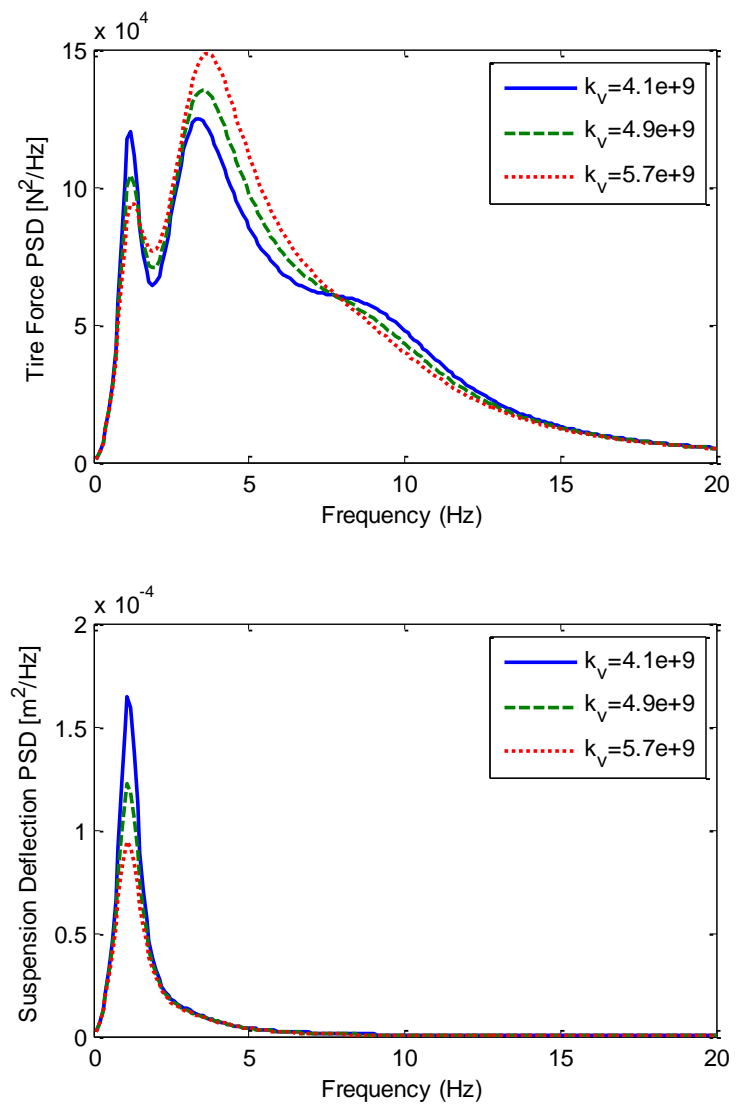

Figure 5: Tyre force and suspension deflection PSDs with cylinder valve loss coefficient variation (in $\mathrm{kg} / \mathrm{s} . \mathrm{m}^{4}$ )
The effect of the accumulator valve loss coefficient on ride comfort, and on road holding and working space, is shown in Figures 6 and 7, respectively. The accumulator valves are designed to almost exclusively control the roll damping, and this is reflected in the response plots. The net effect of the accumulator valves on ride performance appears negligible, however. Figure 7 indicates that the accumulator valves have little influence on working space, but a significant effect on road holding. A larger loss coefficient leads to poorer road holding over most of the frequency range.

Figures 8 and 9 show the dynamic performance effects of fluid viscosity variation. The viscosity values have been chosen to represent the hydraulic oil at $-30^{\circ} \mathrm{C}$, $30^{\circ} \mathrm{C}$ and $100^{\circ} \mathrm{C}$. It is clear that the largest viscosity value $\left(-30^{\circ} \mathrm{C}\right)$ alters the system response sharply, whereas the responses corresponding to the two smaller viscosity values have much more subtle differences. A large fluid viscosity has a net negative effect on ride comfort and road holding, but a positive effect on working space.
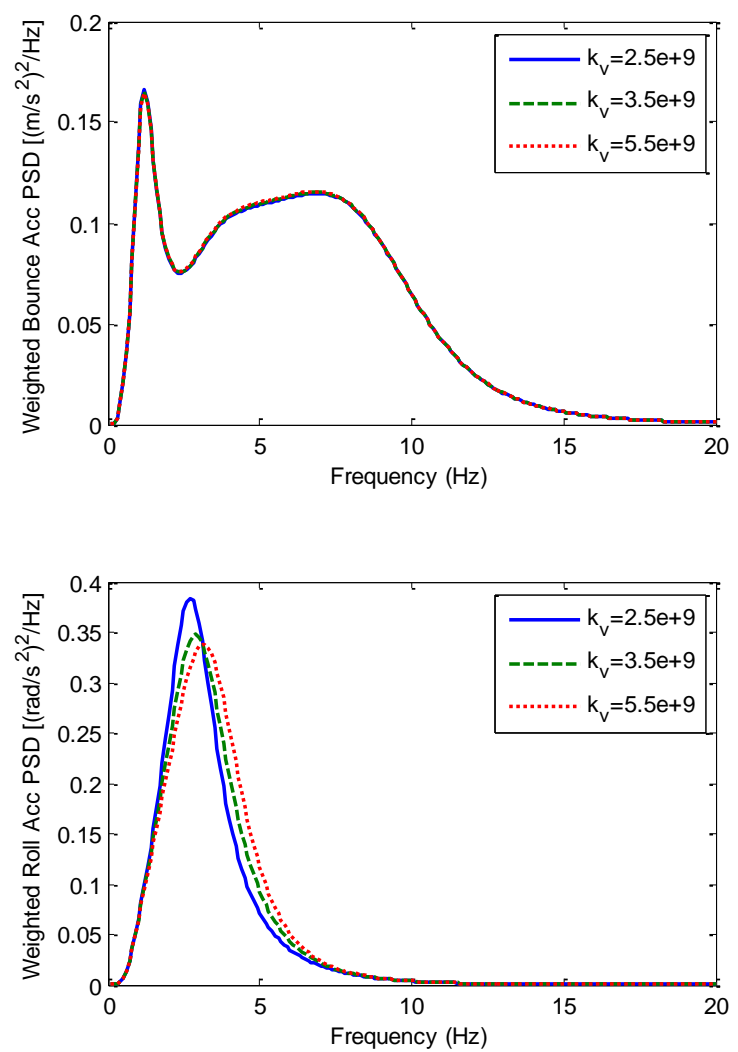

Figure 6: Acceleration PSDs with accumulator valve loss coefficient variation (in $\mathrm{kg} / \mathrm{s} . \mathrm{m}^{4}$ ) 

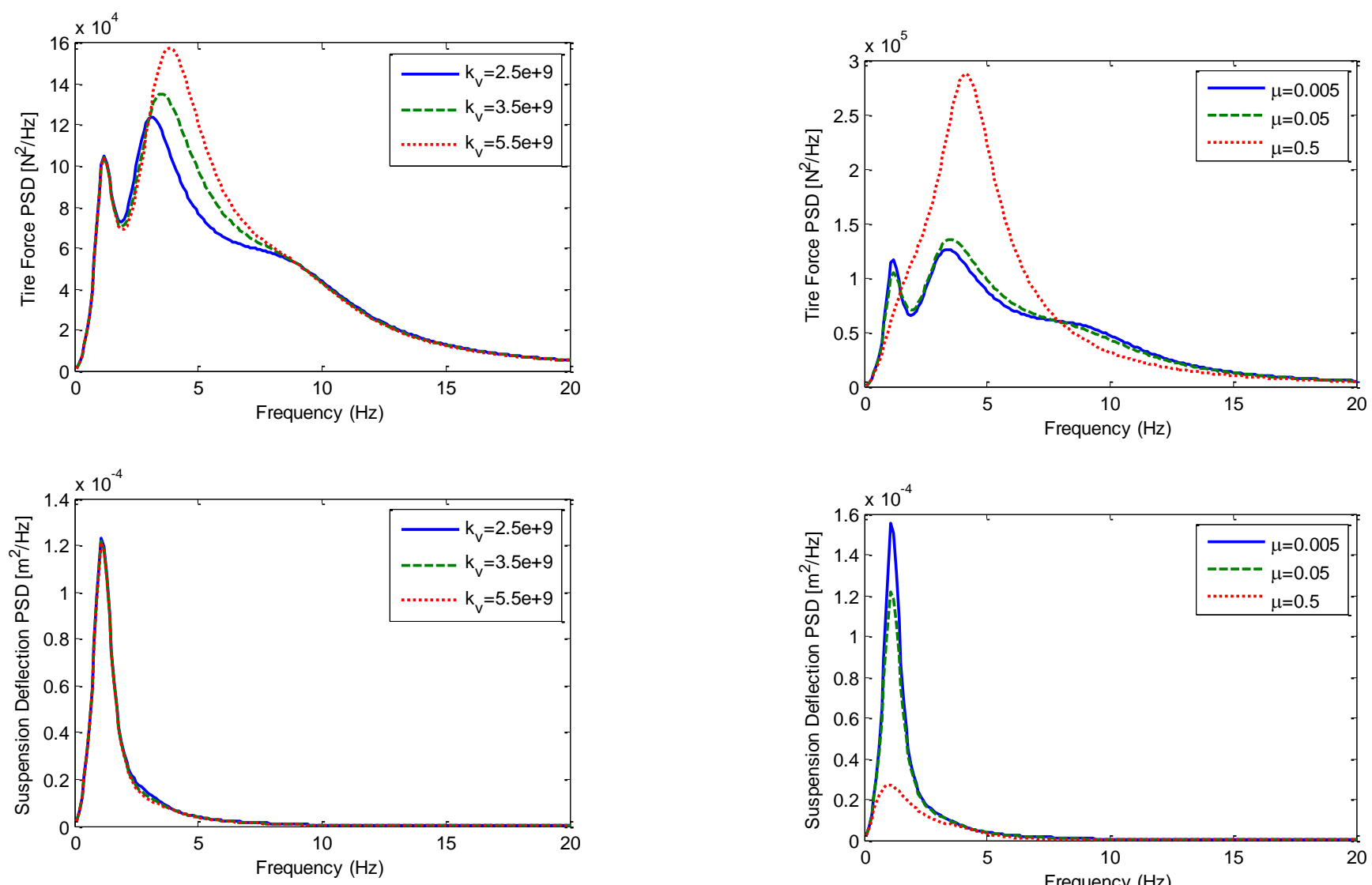

Figure 7: Tyre force and suspension deflection PSDs with accumulator valve loss coefficient variation (in $\mathrm{kg} / \mathrm{s} . \mathrm{m}^{4}$ )

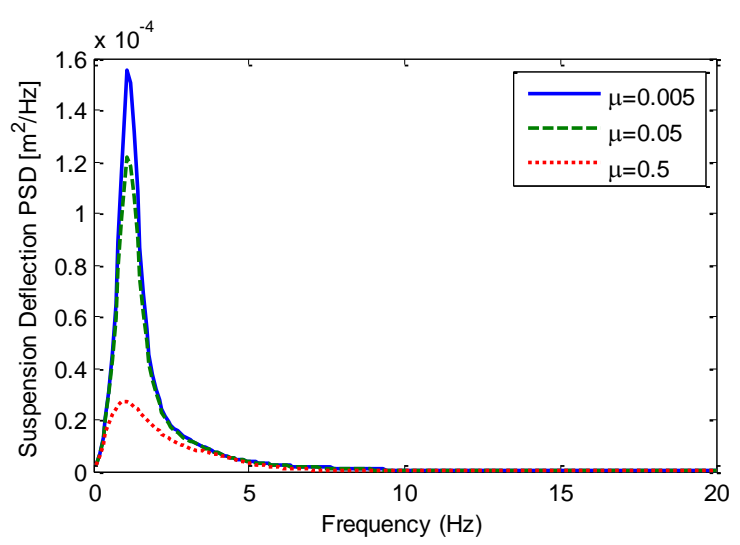

Figure 9: Tyre force and suspension deflection PSDs with hydraulic fluid viscosity variation (in $\left.N . s / m^{2}\right)$
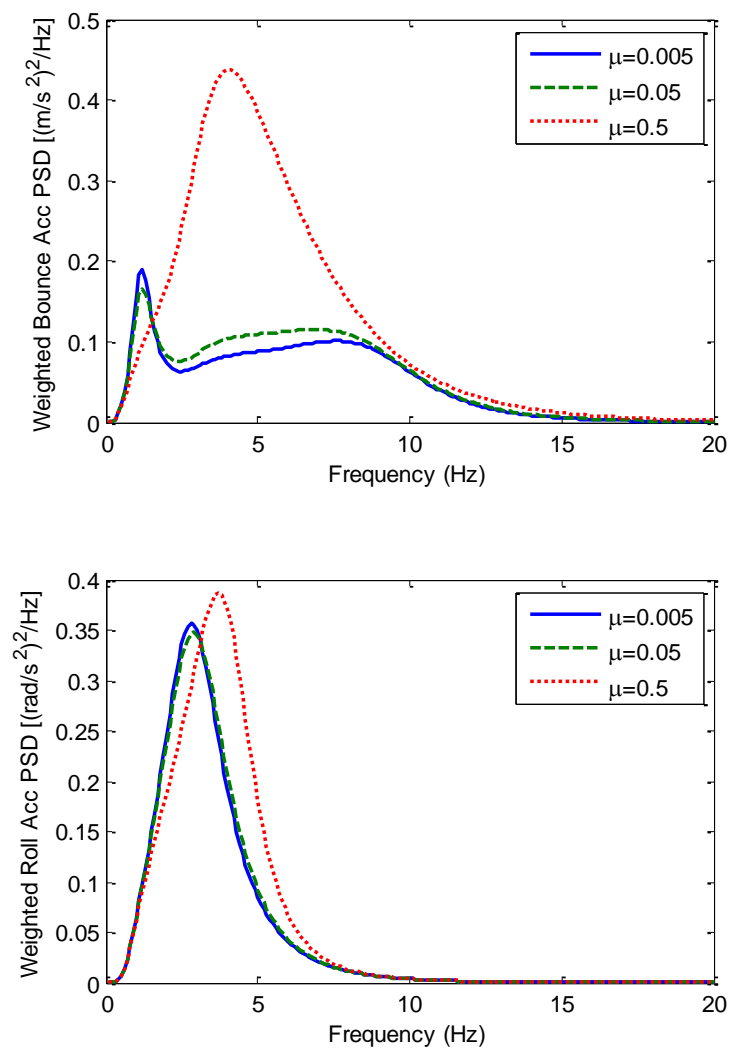

Figure 8: Acceleration PSDs with hydraulic fluid viscosity variation (in $\mathrm{N} . \mathrm{s} / \mathrm{m}^{2}$ )

\section{CONCLUSION}

The results indicate that, while hydraulically interconnected suspension (HIS) systems provide a potentially viable method by which to partially overcome the ride/handling compromise, there are a number of hydraulic system parameters which will considerably affect a vehicle's ride performance.

The four most important of these parameters, at least in the context of a simplified half-car model, are: mean system pressure; cylinder valve loss coefficient; accumulator valve loss coefficient; and fluid viscosity. These parameters influence the vehicle's ride, road holding, and working space performance in a significant yet varied manner. This has a number of implications for HIS system design, such as tolerance and manufacturing specifications, and recommended system working conditions.

Recommendations for future work include the extension of the study to a full-car system, the use of other interconnection arrangements and model parameters, and the modelling of vehicle lateral dynamics to give a more thorough indication of handling performance. Experimental validation of the findings is also recommended. 


\section{ACKNOWLEDGMENTS}

Financial support for this research was provided jointly by the Australian Research Council (ARC LP0562440) and the University of Technology, Sydney.

\section{REFERENCES}

[1] M.C. Smith, G.W. Walker, Interconnected Vehicle Suspension. Journal of Automobile Engineering 219 (3) (2005) 295-307.

[2] J. Fontdecaba, Integral Suspension System for Motor Vehicles Based on Passive Components. SAE Technical Paper Series SAE 2002-01-3105 (2002).

[3] J.R. Wilde, G.J. Heydinger, D.A. Guenther, T. Mallin, A.M. Devenish, Experimental Evaluation of Fishhook Maneuver Performance of a Kinetic Suspension System. SAE Technical Paper Series SAE 2005-01-0392 (2005).

[4] W. Smith, N. Zhang, J. Jeyakumaran, Ride Simulations of a Half-car with a Hydraulically Interconnected Passive Suspension. FISITA-2006 World Automotive Congress, Japan (2006).

[5] J. Jeyakumaran, W. Smith, N. Zhang, Transient Performance of a Hydraulically Interconnected Suspension System. FISITA-2006 World Automotive Congress, Japan (2006).

[6] P.J. Liu. (1994). "An Analytical Study of Ride and Handling Performance of an Interconnected Vehicle Suspension," M.A.Sc. Thesis, Concordia University.

[7] M. Ortiz, Principles of Interconnected Suspensions. RaceCar Engineering 7 (7-8) (1997).

[8] M. Gobbi, G. Mastinu, Analytical Description and Optimization of the Dynamic Behaviour of Passively Suspended Road Vehicles. Journal of Sound and Vibration 245 (3) (2001) 457-481.

[9] "ISO 2631-1:1997 Evaluation of human exposure to whole-body vibration - Part 1: General requirements."

[10] B. Mashadi, D.A. Crolla, Influence of ride motions on the handling behaviour of a passenger vehicle. Proceedings of the Institute of Mechanical Engineers, Part D, Journal of Automobile Engineering 219 (9) (2005) 1047-1058.
[11] A.W. Burton, A.J. Truscott, P.E. Wellstead, Analysis, modelling and control of an advanced automotive selflevelling suspension system. IEE Proc. Control Theory Appl. 142 (2) (1995) 129-139.

[12] D.E. Newland, An Introduction to Random Vibrations and Spectral Analysis, Longman, London, 1975.

[13] C.J. Dodds, J.D. Robson, The Description of Road Surface Roughness. Journal of Sound and Vibration 31 (2) (1973) 175-183.

[14] A.N. Heath, Application of the Isotropic Road Roughness Assumption. Journal of Sound and Vibration 115 (1) (1987) 131-144.

[15] K.M.A. Kamash, J.D. Robson, The Application of Isotropy in Road Surface Modelling. Journal of Sound and Vibration 57 (1) (1978) 89-100.

[16] K.M.A. Kamash, J.D. Robson, Implications of Isotropy in Random Surfaces. Journal of Sound and Vibration 54 (1) (1977) 131-145.

[17] J.D. Robson, Road Surface Description and Vehicle Response. International Journal of Vehicle Design 1 (1) (1979) 25-35.

[18] N. Zhang, W.A. Smith, J. Jeyakumaran, Free Vibration of Vehicles with Hydraulically Interconnected Suspensions. Submitted to Journal of Sound and Vibration (2006).

\section{CONTACT}

Wade Smith

Mechatronics and Intelligent Systems

Faculty Of Engineering

University of Technology, Sydney

PO Box 123, Broadway

NSW, Australia

Ph: (02) 95141613

Fax: (02) 95142655

email: wsmith@eng.uts.edu.au 